\title{
Let's talk about sex and endometriosis
}

\author{
Lone Hummelshoj, ${ }^{1}$ Aisha De Graaff, ${ }^{2}$ Gerard Dunselman, ${ }^{3}$ \\ Paolo Vercellini ${ }^{4}$
}

${ }^{1}$ Chief Executive, World Endometriosis Research Foundation, London, and Secretary General, World Endometriosis Society, London, UK

${ }^{2}$ Department of Obstetrics and Gynaecology, Research Institute GROW, Maastricht University Medical Centre, Maastricht,

The Netherlands

${ }^{3}$ Department of Obstetrics and Gynaecology, Research Institute GROW, Maastricht University

Medical Centre, Maastricht,

The Netherlands

${ }^{4}$ Istituto Ostetrico e Ginecologico

"Luigi Mangiagalli", Università

degli Studi di Milano, Milan,

Italy and President, World

Endometriosis Society,

London, UK

\section{Correspondence to}

Ms Lone Hummelshoj, World Endometriosis Research

Foundation, 89 Southgate Road, London N1 3JS, UK;

lone@endometriosis.org

Received 4 February 2013

Revised 23 July 2013

Accepted 24 July 2013

Published Online First

16 October 2013
To cite: Hummelshoj L, De Graaff A, Dunselman G, et al. I Fam Plann Reprod Health Care 2014;40:8-10.

\section{BACKGROUND}

It is a truth universally acknowledged that the main symptoms of endometriosis are pelvic pain and, to a lesser extent, infertility and fatigue. ${ }^{12}$ These symptoms affect an estimated 176 million women worldwide. ${ }^{3}$

What is less frequently acknowledged, however, are the different types of pains associated with symptomatic endometriosis, a disease which constitutes the most frequent origin of the '3D Syndrome'

- Dysmenorrhoea (defined according to loss of work productivity and need for bed rest)

- Dyschezia (defined according to frequency of the complaint) and

- Dyspareunia (defined according to limitation of sexual activity).

Dyspareunia is generally described as deep (pain experienced inside the vaginal canal, at the level of the cervix, or in the pelvic/uterine/abdominal region) or superficial (pain in the vulvar region and/or the vaginal introitus). ${ }^{5}$ However, if sex hurts it is a problem for the woman and the couple regardless of whether the pain is deep or superficial. If something is painful, it is painful, and one will typically wish to avoid it.

\section{FREQUENCY OF DYSPAREUNIA IN WOMEN WITH ENDOMETRIOSIS}

Women with endometriosis have a ninefold increase in risk of deep dyspareunia in comparison to the general female population of corresponding age. ${ }^{6}$ In two groups of women with recto-vaginal endometriosis $(n=100)$ and peritoneal and/or ovarian endometriosis $(n=100)$ compared to healthy controls $(n=100)$, $67 \%$ and 53\%, respectively, reported deep dyspareunia compared with $26 \%$ of controls.

Whilst recognising that dyspareunia is found in populations without endometriosis, this study demonstrated that women with endometriosis experience more frequent and severe deep dyspareunia and worse sexual functioning compared with women without endometriosis. Differences between women with diverse endometriosis forms are, however, marginal. ${ }^{7}$

In a market research survey of 2753 women, with symptomatic endometriosis or suspected (symptomatic of) endometriosis, $50 \%$ responded that the single largest impact on their quality of life was that of their compromised sex lives. ${ }^{8}$

An international cross-sectional survey, involving 12 centres in 10 countries, investigating the quality of life of women with surgically diagnosed endometriosis $(n=931)$ reported that $28 \%$ had originally presented with dyspareunia as one of their primary symptom. Some $47 \%$ suffered with painful sex at the time of the survey. Of these, $61 \%$ reported pain often or always, and 54\% would either interrupt or avoid intercourse all together due to their pain. ${ }^{9}$ Furthermore, those with dyspareunia (as well as those with chronic pelvic pain) had significantly lower scores on both the physical and mental components of the Short Form 36 Version 2 (SF36-v2), which was used to measure quality of life on all aspects of endometriosis in this survey. ${ }^{9}$

In addition, not only do these women with endometriosis battle with the painful symptoms of the disease, but they can be left with issues concerning their body image and self-esteem, consequent psychological issues, and further consequential relationship problems. None of these issues are aided by today's perpetual bombardment through the popular press, TV and/or glamour magazines when it comes to the improbable promotion of body images and what sex should and/or could be like.

So, what we observe happening in a population of women, who should be quite sexually active at this particular time of their lives, is a severely compromised sex life due to dyspareunia. And, if these women are not having sex, it doesn't just affect them, it affects their partners as well. 


\section{THE TRAUMATISED COUPLE}

Whereas severe dysmenorrhoea contributes to absence from work and/or reduced productivity, ${ }^{10}{ }^{11}$ painful intercourse - and a consequent lack of intercourse may lead to substantial psychological and relational distress contributing to infidelity, relationship dissolution and divorce.

In two separately designed studies, 50\% and 56\% of women reported that endometriosis had affected their relationships, causing a split in $10 \%$ and $8 \%$ of cases, respectively. ${ }^{9} 12$

\section{SEX: A HUMAN RIGHT?}

In 2002, the World Health Organization (WHO) published a 'Report of a Technical Consultation on Sexual Health'. ${ }^{13}$ Within this, 'reproductive health' was defined as "a state of complete physical, mental, and social well-being and not merely the absence of disease or infirmity, in all matters relating to the reproductive system and to its functions and processes". Reproductive health therefore implies that people are able to have a satisfying and safe sex life and that they have the capacity to reproduce and the freedom to decide if, when, and how often to do so. In other words: sexual rights are reproductive rights. And, according to the $\mathrm{WHO},{ }^{13}$ these sexual rights embrace human rights that are already recognised in national law, including the right of all persons to pursue a satisfying and pleasurable sexual life.

\section{WHAT CAN BE DONE ABOUT ENDOMETRIOSIS-RELATED DYSPAREUNIA?}

Dyspareunia is an ideal candidate for doctor shopping, uncoordinated multiple treatment attempts, and low adherence to strategies that do not show immediate effects. Thus dyspareunia may also have a financial and personal cost associated with the complaint, which can be a challenge to treat.

First, it has to be emphasised that the partners of women with endometriosis should be intensely involved in the management of the disease from the beginning. Proper counselling of the woman and her partner on the nature of the disease and its potential consequences for their sex life could hopefully diminish the sexual burden for these couples.

Second, physicians need to be mindful of the fact that many women may not voluntarily disclose what is, after all, very personal and intimate information. Even caring and inquisitive physicians may have difficulty explicitly exploring this aspect of a woman's medical history. However, by asking probing (and potentially awkward) questions, a physician may hone in faster on the real problem and thus be in a better position to advise on appropriate solutions long term, including a multidisciplinary approach and self-help resources. Such questions include whether the woman experiences cyclical pain, pain with different sexual positions, pain at entry, and pain at either - or both - shallow and deep penetration. Pain immediately after, and up to 24 hours after intercourse, is an issue for many women also.

Third, be mindful that there is no immediate medical solution. Surgery or medical treatment with norethisterone acetate for dyspareunia provide improvement of only $43 \%$ and $59 \%$, respectively, at 12 months, ${ }^{14}$ and the side effect profile of medical treatments cannot be ignored. Painful sex appears to be substituted by a loss of libido, as observed in $20 \%$ of cases, ${ }^{14}$ and so such treatments cannot be hailed as an improvement in the sex lives of this particular group of women.

What also needs to be taken into consideration is the fact that dyspareunia may be a consequence of treatment, and not an initial complaint. Aggressive (and at times unnecessary) surgery, such as bowel resections and resection of large parts of the uterosacral ligaments with consequent scarring of the pouch of Douglas, can adversely contribute to an impaired sex life. ${ }^{15}$ Women should therefore always be counselled appropriately prior to surgery so that they are aware of these potential risks. Furthermore, advice should be heeded from the recently published consensus on the current management of endometriosis, that those women with a higher stage of disease and/or intractable clinical problems should receive care from a centre of expertise with appropriate surgical expertise in the laparoscopic excision of endometriosis. ${ }^{2}$

Finally, it is worth bearing in mind that improving symptoms may not be sufficient when dealing with dyspareunia. To use the analogy of being hit by a hammer: it hurts. It hurts less, however, to be hit by stick - but it still hurts. Anyone would avoid any kind of pain if at all possible. Thus reducing the pain alone is not necessarily enough when it comes to improving the sex lives of women with endometriosis and their partners. Less pain may be all good and well, but if sex still hurts - it hurts. Engaging a wider team of sexologists, pain specialists, physical therapists and psychologists may be advisable when dealing with the challenge of dyspareunia.

\section{CONCLUSIONS}

Dyspareunia affects mainly young women in their most sexually active years, which may compromise their fertility in addition to struggling with the painful symptoms of endometriosis.

If $50 \%$ of women with endometriosis report dyspareunia as a major, persistent complaint then it is time to start addressing this particular symptom specifically, rather than studying symptomatic women with endometriosis as an undifferentiated population. With the latter, important distinctions between subgroups with specific symptoms, such as dyspareunia, may be masked, which consequently may interfere with clinical understanding and therapeutic decision-making. ${ }^{4}$ 
Dyspareunia should at all times be viewed in a broader clinical perspective, considering potential psychological and interpersonal consequences. A multidisciplinary perspective is essential when developing individual treatment pathways for this incredibly large group of afflicted women and their partners.

\section{Competing interests None.}

Provenance and peer review Not commissioned; externally peer reviewed.

\section{REFERENCES}

1 Kennedy S, Bergqvist A, Chapron C, et al. ESHRE guideline for the diagnosis and treatment of endometriosis. Hum Reprod 2005;20:2698-2704.

2 Johnson NP, Hummelshoj L, for the World Endometriosis Society Montpellier Consortium. Consensus on current management of endometriosis. Hum Reprod 2013;28: 1552-1568.

3 Adamson D, Kennedy SH, Hummelshoj L. Creating solutions in endometriosis: global collaboration through the World Endometriosis Research Foundation. J Endometriosis 2010;2:3-6.

4 Vercellini P, Meana M, Hummelshoj L, et al. Priorities for endometriosis research: a proposed focus on deep dyspareunia. Reprod Sci 2011;18:114-118.

5 Meana M, Binik YM. Dyspareunia: causes and treatments. In: Vercellini P (ed.), Gynecology in Practice. Chronic Pelvic Pain. Oxford, UK: John Wiley \& Sons, 2011:125-136.

6 Ballard KD, Seaman HE, de Vries CS, et al. Can symptomatology help in the diagnosis of endometriosis? Findings from a national case-control study-Part 1. BJOG 2008;115:1382-1391.
7 Vercellini P, Somigliana E, Buggio L, et al. "I can't get no satisfaction": deep dyspareunia and sexual functioning in women with rectovaginal endometriosis. Fertil Steril 2012;98:1503-1511.

8 Bernuit D, Ebert A, Halis G, et al. Female perspectives on endometriosis: findings from the uterine bleeding and pain women's research study. J Endometriosis 2011;3:73-85.

9 De Graaff A, D'Hooghe TM, Dunselman GAJ, et al. The significant effect of endometriosis on physical, mental and social wellbeing: results from an international cross-sectional survey. Hum Reprod 2013; 11 July [Epub ahead of print].

10 Nnoaham KE, Hummelshoj L, Webster P, et al. Impact of endometriosis on quality of life and work productivity: a multi-center study across ten countries. Fertil Steril 2011;96:366-373

11 Simoens S, Dunselman G, Dirksen C, et al. The burden of endometriosis: costs and quality of life of women with endometriosis treated in referral centres. Hum Reprod 2012;27:1292-1299.

12 Fagervold B, Jenssen M, Hummelshoj L, et al. Life after a diagnosis of endometriosis - a 15-year follow-up study. Acta Obstet Gynecol Scand 2009;88:914-919.

13 World Health Organization. Defining Sexual Health: Report of a Technical Consultation on Sexual Health, 28-31 January 2002, Geneva. http://www.who.int/reproductivehealth/topics/ gender_rights/defining_sexual_health.pdf [accessed 9 April 2012].

14 Vercellini P, Somigliana E, Consonni E, et al. Surgical versus medical treatment for endometriosis-associated severe deep dyspareunia: I. Effect on pain during intercourse and patient satisfaction. Hum Reprod 2012;27:3950-3959.

15 Roman H, Loisel C, Resch B, et al. Delayed functional outcomes associated with surgical management of deep rectovaginal endometriosis with rectal involvement: giving patients an informed choice. Hum Reprod 2010;25:890-899. 